\title{
Uma Investigação sobre o Campo de Atuação dos Licenciados em Computação do Polo de Apoio Presencial em Mauriti/CE
}

\author{
Lucas Luan de Araújo Freitas ${ }^{1 *}$, Emmanuel Sávio Silva Freire ${ }^{2 \dagger}$ \\ ${ }^{1}$ Polo de Apoio Presencial - Universidade Estadual do Ceará (UECE) \\ Caixa Rua Padre Argemiro Rolim de Oliveira, s/n - 63.210-000 - Mauriti - CE - Brasil \\ ${ }^{2}$ Departamento de Ensino - Instituto Federal do Ceará (IFCE) \\ Morada Nova - CE - Brasil \\ lucas.luandaluno.uece.br, savio.freiredifce.edu.br
}

\begin{abstract}
The licensees in Computing have diverse possibilities of fields performance due to its formation. However, are the fields of performance limited to those foreseen in the Pedagogical Project of the Course (PPC)? In this sense, this study aimed to reveal the area of activity of graduated students of Degree in Computer offered by the State University of Ceará (UECE) in the presence support place situated in Mauriti/CE. Therefore, a descriptive research was carried out, which used a questionnaire as a collection instrument. The participants of the research were the graduates of the aforementioned course. As a main result, it was found that all the fields of performance suggested in the PPC were occupied by at least one licensee participating in the research.
\end{abstract}

Resumo. Os licenciados em Computação possuem diversas possibilidades de campos atuação devido a sua formação. Entretanto, será que os campos de atuação se limitam aos previstos no Projeto Pedagógico do Curso (PPC)? Neste sentido, o presente trabalho teve como objetivo desvelar a área de atuação dos alunos egressos do curso de Licenciatura em Computação ofertado pela Universidade Estadual do Ceará (UECE) no polo de apoio presencial situado em Mauriti/CE. Para tanto, foi realizada uma pesquisa descritiva, que utilizou um questionário como instrumento de coleta. Os participantes da pesquisa foram os egressos do curso supracitado. Como principal resultado, foi encontrado que todos os campos de atuação sugeridos no PPC foram ocupados por pelo menos um licenciado participante da pesquisa.

\section{Introdução}

Com o crescente avanço da tecnologia, observa-se o quanto as Tecnologias de Informação e Comunicação (TIC) estão sendo utilizadas na educação, possibilitando que o processo de ensino e aprendizagem seja mais dinâmico e lúdico. Neste sentido, o uso das TIC, como os Ambientes Virtuais de Aprendizagem (AVA) e os softwares educativos, é dificultada devido à falta de formação técnica e pedagógica da maioria dos

\footnotetext{
* Licenciado em Computação pela Universidade Estadual do Ceará (UECE).

$\dagger$ Professor do Instituto Federal do Ceará (IFCE/Campus Morada Nova) e colaborador do curso de Licenciatura em Computação da UECE. Mestre em Ciências da Computação.
} 
VII Congresso Brasileiro de Informática na Educação (CBIE 2018)

Anais dos Workshops do VII Congresso Brasileiro de Informática na Educação (WCBIE 2018)

docentes e ao pouco conhecimento dessas ferramentas por parte de gestores [Paiva et al. 2017] [Rapkiewicz et al. 2004].

Além disso, a educação brasileira não tem capacitado os profissionais da educação básica na área da Informática, pois muitos destes relatam que não fazem uso das novas tecnologias como metodologias em suas aulas devido à falta dessa formação nos seus cursos de graduações [Públio Junior 2018]. Portanto, é notória a necessidade de um profissional com essa formação para atuar nesse contexto.

Nesse sentido, o curso de Licenciatura em Computação apresenta formas de integrar a educação com as novas tecnologias, proporcionando que (i) a área educacional apresente melhorias no processo de ensino e aprendizagem e (ii) seus egressos possam atuar em diversos campos de atuação. Assim, sabe-se que o profissional licenciado em Computação pode ministrar aulas, principalmente, no Laboratório Escolar de Informática (LEI) disponibilizado nas escolas e exercer funções técnicas desenvolvidas em empresas de desenvolvimento e/ou manutenção de software [Araújo 2010]. Devido a essa formação, existe uma dificuldade do egresso em definir a sua identidade profissional, indicando o que deve ensinar, quais os possíveis campos de atuação e como deve ser a adequação pedagógica dentro das escolas [Santos, Silva e Hinterholz 2017]. Logo, é importante analisar a realidade vivenciada pelos egressos do referido curso no mundo do trabalho, possibilitando compará-la com os campos de atuação que são definidos no Projeto Pedagógico do Curso (PPC).

Nessa perspectiva, o presente trabalho teve como objetivo desvelar a área de atuação dos alunos egressos do curso de Licenciatura em Computação ofertado pela Universidade Estadual do Ceará (UECE) no polo de apoio presencial situado em Mauriti/CE. Mais especificamente, essa pesquisa objetivou: (i) identificar quais as possíveis áreas de atuação dos egressos do curso de Licenciatura em Computação, (ii) verificar quais as áreas de atuação exercidas pelos egressos do referido curso, e (iii) comparar as duas áreas de atuação: possíveis e reais. Vale salientar que os resultados dessa pesquisa podem auxiliar na evolução do perfil do licenciado em Computação e, consequentemente, na adequação do PPC dos cursos que esse profissional é oriundo.

A pesquisa realizada foi descritiva, que utilizou um questionário como instrumento de coleta. $\mathrm{O}$ estudo considerou apenas os egressos do referido curso formados no polo situado em Mauriti. Os dados obtidos a partir do questionário aplicado foram complementados com pesquisas existentes na literatura que abordaram sobre os campos de atuação dos licenciados em Computação. Adicionalmente, este artigo está organizado como segue. A seção 2 apresenta os conceitos relacionados ao perfil do licenciado em Computação. O curso de licenciatura em Computação da UECE é retratado na seção 3. Na seção 4, são detalhados os trabalhos relacionados. A metodologia utilizada é abordada seção 5. Na seção 6, são expostos os resultados e as discussões relacionados aos campos de atuação dos licenciados em Computação. Finalmente, as considerações finais e os agradecimentos são apresentados nas seções 7 e 8, respectivamente.

\section{O Perfil do Licenciado em Computação}

O aluno do curso de Licenciatura em Computação detém ao decorrer do referido curso a construção de estratégias e capacidades que torna este profissional capaz de utilizar inovação tecnológica e habilidades pedagógicas, permitindo assim a compreensão 
sistemática do ensino e aprendizagem em diversos setores [Rapkiewicz et al. 2004]. Além disso, [Araújo 2010] indica que tal profissional incorpora competências e saberes tais como a criatividade e inovação, pois devem ser "capazes de promover o desenvolvimento da interdisciplinaridade entre as diversas disciplinas que formam o currículo escolar, onde o licenciado em Computação orientará os outros docentes da instituição educacional a utilizar as ferramentas tecnológicas ali existentes, ensinando-lhes a obter daqueles equipamentos o seu máximo potencial, sempre voltado à educação”.

Logo, o licenciado em Computação torna-se capaz de atuar em diversas áreas, desde a sua função como docente buscando a integração e interdisciplinaridade sobre o uso das TIC como também na construção e desenvolvimentos de softwares educativos. Além disso, é capaz de promover a formação de outros docentes para a melhor utilização de equipamentos tecnológicos em sala de aula [Araújo 2010]. Assim, os docentes que não possuem formação para a utilização das TIC podem obter capacitação voltada as necessidades presentes na sua função.

Além disso, [Luciano e Santos 2013], baseando-se no Currículo Referência para Cursos de Licenciatura em Computação elaborado pela Sociedade Brasileira de Computação (SBC), indicaram que o curso de "Licenciatura em Computação almeja a formação profissional docente, e engloba conhecimentos pertinentes à área de Sistemas de Computação e suas aplicações". Portanto, além da base pedagógica, o licenciado em Computação deve possuir um bom embasamento técnico.

\section{O Curso de Licenciatura em Computação oferecido pela UECE}

A Universidade Estadual do Ceará (UECE) vem ofertando o curso de licenciatura em Computação, na modalidade Educação a Distância $(\mathrm{EaD})$ em parceria com a Universidade Aberta do Brasil (UAB). Segundo [Sampaio 2014], a UAB foi criada pelo Ministério da Educação (MEC) com o objetivo de atender à demanda de formação de professores para a rede pública de ensino. Assim, considerando o crescente desenvolvimento das tecnologias digitais e a resolução $\mathrm{N}^{\mathrm{o}}$ 3156-CEPE, de 18 de novembro de 2008, a UECE implantou o curso de Graduação Licenciatura em Informática nos municípios de Mauriti, Missão Velha e Tauá [Sampaio 2014]. Em 2014, o PPC do curso foi alterado e passou a denominar-se Licenciatura em Computação. Atualmente, esse curso é ofertado em nove polos distribuídos no estado do Ceará, dentre eles, o polo situado em Mauriti.

De acordo com o PPC do referido curso, o seu objetivo é "propiciar uma formação sólida e abrangente de educadores, com base nas áreas de Computação e técnicas de Informática, enfatizando aspectos científicos, técnicos, pedagógicos e sociais; Visa a geração de inovações no processo da formação de educadores para a educação básica, preparando-os para o exercício do magistério suportado por tecnologias de Informática e fundamentos de Computação" [Sampaio 2014].

Além disso, o curso foi estruturado nos seguintes eixos curriculares: (i) Núcleo de formação básica, que compreende os princípios básicos da área de Computação; (ii) Núcleo de formação tecnológica, que possibilita aplicar os conhecimentos básicos no desenvolvimento tecnológico da Computação; (iii) Núcleo de formação humanística, que permitem a formação na dimensão social e humana; (iv) Núcleo comum, que engloba conhecimentos teóricos e práticos, abordados pelas disciplinas instrumentais; (v) Núcleo pedagógico, que permite que o aluno diversifique suas opções, se envolvendo 
VII Congresso Brasileiro de Informática na Educação (CBIE 2018)

Anais dos Workshops do VII Congresso Brasileiro de Informática na Educação (WCBIE 2018)

formalmente com outros tipos de atividades, como Atividades Científico-Culturais Complementares (ACC) e Prática como Componente Curricular (PCC); (vi) Estágio supervisionado, no qual está presente a efetivação da integração teoria-prática e o aprofundamento da relação ação-reflexão-ação; e (vii) Trabalho de Conclusão de Curso (TCC), no qual o aluno terá que elaborar um trabalho original, a partir das experiências vivenciadas nas disciplinas de Estágio Supervisionado nos Ensino Fundamental ou no Ensino Médio, em forma de monografia ou artigo científico.

Adicionalmente, o PPC indica que o profissional formado pelo referido curso pode atuar nos seguintes campos de atuação: (i) pesquisa em tecnologia na área da Informática, (ii) criação, utilização e avaliação de software educacional, (iii) elaboração e participação em projetos na área de Ensino a Distância (EAD), (iv) desenvolvimento de materiais instrucionais através do emprego da Informática, (v) organização e administração de laboratórios de Informática, (vi) assessoria às instituições educativas que constroem Propostas Pedagógicas, (vii) capacitação de professores e comunidade escolar, segundo critérios da escola para trabalhar com Informática educativa, e (viii) elaboração de materiais didático-pedagógicos.

\section{Trabalhos Relacionados}

Nesta seção, são apresentados os trabalhos correlatos com o objetivo da presente pesquisa. Para tanto, foram considerados trabalhos que retratavam a área de atuação dos alunos oriundos dos cursos de Licenciatura em Informática/Computação.

O trabalho de [Rapkiewicz et al. 2004] realizou uma análise do estágio atual da Educação em Informática para verificar a necessidade da criação de um curso de Licenciatura em Computação na região do Norte Fluminense. Para tanto, foi apresentado um exemplo para a implantação de curso de licenciatura e bacharelado na área da Informática, destacando os possíveis postos de trabalho a ser ocupados pelos egressos desses cursos. Como resultado, foi constatada a existência de um amplo espaço no mercado de trabalho, principalmente com o advindo das novas tecnologias e a necessidade de se ter profissionais da área de Computação e Informática, não só na região em estudo, mas também, em localidades próximas como na área metropolitana da capital do estado.

A pesquisa de [Luciano e Santos 2013] abordou sobre o nível de satisfação dos licenciados em Computação, os seus principais campos de trabalho e as suas percepções da área. Assim, os autores fizeram uma pesquisa no estado da Paraíba, analisando o mercado, suas oportunidades e seus desafios. Como resultados, a pesquisa atestou que (i) o egresso em licenciatura da Computação está habilitado para o mercado em qualquer campo de atuação que tenha como especificidade conhecimentos em sistemas de Computação e mediação pedagógica com a usabilidade de ferramentas digitais e tecnológicas, (ii) todos os participantes se encontravam no mercado de trabalho, e (iii) cerca de $66 \%$ dos egressos participaram de cursos de pós-graduação, e, em sua maioria, já tinham terminado os cursos de mestrado e doutorado.

A investigação de [Santos, Silva e Hinterholz 2017] estudaram sobre os desafios e as oportunidades para o curso de Licenciatura em Computação, evidenciando uma pesquisa realizada online que englobou licenciandos e egressos dos cursos de Licenciatura em Computação do Brasil. Caracterizado como quantitativo, o estudo utilizou um questionário de 22 questões como instrumento de pesquisa. Como 
VII Congresso Brasileiro de Informática na Educação (CBIE 2018)

Anais dos Workshops do VII Congresso Brasileiro de Informática na Educação (WCBIE 2018)

resultados, foram identificados as expectativas e os desejos com relação a formação e a área de atuação do egresso dessa área, onde a integração da teoria com a prática do docente ainda é um desafio. Além disso, os alunos também apontaram a dificuldade de associar o que é estudado com as práticas pedagógicas.

Com base nos trabalhos apresentados, pode-se notar que a variedade de campos de atuação dos licenciados em Computação permite que esses profissionais sejam absorvidos pelos mundos do trabalho e acadêmico. Entretanto, essa realidade pode mudar quando o curso é ofertado em cidades do interior, que nem sempre apresenta o mesmo desenvolvimento que nas grandes capitais. Portanto, a análise dos egressos dessas regiões é importante para conhecer o campo de atuação desses egressos.

\section{Metodologia}

Este trabalho pode ser definido como um estudo descritivo e de levantamento, pois envolveu o questionamento direto dos participantes relacionado ao objetivo da presente pesquisa. Mais especificamente, esta pesquisa foi classificada de acordo com as categorias de [Joye 2014]:

- Natureza aplicada, pois busca-se gerar conhecimento para a solução de problemas específicos;

- Abordagens qualitativa e quantitativa, porque utiliza-se tanto a interpretação do fenômeno, quanto recursos estatísticos para apresenta os resultados;

- Descritiva, dado que visa descrever as características de uma determinada população;

- Procedimento de levantamento, visto que envolve a interrogação direta das pessoas cujo comportamento se deseja conhecer; e

- Aplicação de questionário, pois utilizou-se esse instrumento para a coleta de dados.

O local de pesquisa foi o polo de apoio presencial situado em Mauriti/CE e teve como participantes de pesquisa os egressos do curso de Licenciatura em Computação do referido polo. A identificação dos participantes ocorreu por meio do auxílio da coordenação do polo que disponibilizou os meios de contatos de todos os alunos formados. Para a coleta dos dados, foi desenvolvido um questionário ${ }^{1}$ contendo onze questões mistas que consideraram o perfil do egresso definido no PPC do curso da UECE. Além disso, o questionário foi disponibilizado via Google Formulário ${ }^{2}$ para o email e aplicativos de mensagens instantâneas dos egressos.

\section{Resultados e Discussões}

Conforme descrito na Seção 5, os dados foram obtidos por meio da aplicação de um questionário. Assim, foi solicitada a colaboração da coordenação do polo de apoio presencial para disponibilizar o contato dos egressos. Segundo a coordenação do polo

1 O questionário utilizado está disponível em: https://drive.google.com/file/d/1iDRzSP-StXb1FRNohdVAxIUQiGW2BkZ/view?usp=sharing.

${ }^{2}$ https://www.google.com/forms/about/ 
VII Congresso Brasileiro de Informática na Educação (CBIE 2018)

Anais dos Workshops do VII Congresso Brasileiro de Informática na Educação (WCBIE 2018)

situado em Mauriti/CE, foram formados 30 licenciados em Informática/Computação. Dentre eles, foram contatados 24 licenciados. Todavia, 12 deles responderam ao questionário. Assim, a presente pesquisa considerou uma amostra que representa $40 \%$ do universo composto por todos os alunos formados pelo polo supracitado. Essa amostra foi formada por alunos egressos com idade entre 24 a 50 anos, $75 \%$ do sexo masculino e que se formaram entre os anos de 2013 e 2017.

Inicialmente, os participantes da pesquisa foram questionados em relação à formação acadêmica recebida durante o curso. Sobre a utilização das TIC na educação, todos os egressos concordaram que a inclusão das TIC no processo de ensino e aprendizagem é importante, pois "elas fazem parte do nosso cotidiano, seja de forma simples ou não" (Formado 1). Essa justificativa corrobora com [Rapkiewicz et al. 2004], pois indicam que essa habilidade de utilização das TIC pode ser comparada com a capacidade de ler e escrever. Além disso, foi realizada a análise das justificativas apresentadas pelos egressos. Essa análise dividiu as respostas em grupos de acordo com a extração da abordagem de cada resposta. Assim, foi encontrado que 41,7\% reconheceram as TIC como uma nova metodologia no processo de ensino e aprendizagem, $41,7 \%$ indicaram que elas são importantes pois fazem parte do cotidiano do aluno, e 16,6\% afirmaram que as TIC auxiliam na aproximação do contexto do aluno.

Os licenciados também admitiram que receberam formação suficiente para conseguir lecionar Computação e Informática nos ensinos fundamental, médio e profissionalizante. Também afirmaram que se sentem aptos a atuar na área de Informática educativa. O Formado 2 argumentou que "ao longo do curso adquirimos conhecimento teórico e prático para o exercício dessa função em sala de aula, bem como no dia a dia, já que a atribuição do educador se estende à vida particular". Esse ponto de vista é confirmado por [Paiva et al. 2017], pois indicaram que "[...] a formação do profissional por meio do curso de Licenciatura em Computação está além dos conhecimentos de natureza científica e tecnológica, envolve também uma terceira dimensão formativa: o conhecimento pedagógico". Adicionalmente, o Formado 10 evidenciou a formação em Informática educativa, pois "já que todas as disciplinas foram voltadas para o processo de ensino e na maioria teóricas com ferramentas disponivel e utilizada no processo de ensino fundamental e médio".

Com a colaboração dos entrevistados, esta pesquisa também buscou-se compreender quais as habilidades/competências que foram desenvolvidas por eles durante o curso. Esse questionamento permitiu conhecer a formação base do profissional da área de licenciatura da Computação, tendo em vista que ele tem acesso a vários campos de atuação. Esse aspecto foi exposto por [Rapkiewicz et al. 2004] que discorreram que "além de qualificados para exercer a (sic) docência em computação no ensino básico, estarão preparados para colaborar nas outras atividades da realidade escolar [...]". O resultado dessa questão é apresentado na Tabela 1.

Assim, é possível perceber que a maioria dos entrevistados concordaram totalmente que analisar e escolher softwares educativos para o processo de ensino e aprendizagem foi uma habilidade/competência desenvolvida por eles durante o curso, bem como concordaram parcialmente que a ampla formação prática tecnológica em Computação foi produzida durante o período do estudo. Entretanto, uma parcela 
VII Congresso Brasileiro de Informática na Educação (CBIE 2018)

Anais dos Workshops do VII Congresso Brasileiro de Informática na Educação (WCBIE 2018)

significativa dos alunos respondeu discordar parcialmente em ter habilidade/competência de desenvolver softwares educativos para treinamento.

Em seguida, os entrevistados foram perguntados se as disciplinas da matriz curricular do seu curso foram suficientes para desenvolver habilidades/competência expostas na Tabela 1 . Dos participantes, $83,3 \%$ afirmaram que sim à questão proposta. Além disso, foi solicitado que os participantes justificassem se não concordassem com a pergunta. Logo, eles informaram que o curso deveria ofertar disciplinas para o desenvolvimento de software, deveria focar mais na inclusão das novas tecnologias e no ensino médio e profissionalizante. Entretanto, um deles salientou que "não era necessário incluir novas disciplinas, mas sim modelar as já existentes" (Formado 4).

\section{Tabela 1. Habilidades e competências desenvolvidas}

\begin{tabular}{|c|c|c|c|c|c|}
\hline Habilidades/Competências & DT & DP & IN & $\mathrm{CP}$ & CT \\
\hline \multirow{7}{*}{$\begin{array}{l}\text { Ampla formação teórica tecnológica em computação. } \\
\text { Ampla formação prática tecnológica em computação. } \\
\text { Desenvolvimento de software educativo para o processo } \\
\text { de ensino. } \\
\text { Desenvolvimento de software educativo para } \\
\text { treinamento. } \\
\text { Desenvolvimento de sistemas EaD (Educação à Distância) } \\
\text { para o processo de ensino. } \\
\text { Desenvolvimento de sistemas EaD (Educação à Distância) } \\
\text { para treinamento. } \\
\text { Analisar e escolher softwares educativos para a melhoria } \\
\text { do processo de ensino e aprendizagem. }\end{array}$} & 3 & 0 & 0 & 5 & 4 \\
\hline & 2 & 2 & 0 & 6 & 2 \\
\hline & 2 & 4 & 1 & 2 & 3 \\
\hline & 1 & 5 & 1 & 3 & 2 \\
\hline & 2 & 2 & 0 & 5 & 3 \\
\hline & 1 & 4 & 1 & 4 & 2 \\
\hline & 3 & 0 & 0 & 2 & 7 \\
\hline
\end{tabular}

Sobre os campos de atuação, foi solicitado que os formados indicassem para quais eles se sentiam preparados pelo curso. O resultado desse questionamento é apresentado na Tabela 2. Portanto, é notório que todos eles afirmaram estar preparados para atuar na "organização e administração de laboratórios de Informática" e na "capacitação de professores e comunidade escolar, segundo critérios da escola para trabalhar com Informática educativa".

Tabela 2. Campos de atuação que se sentem preparados

\begin{tabular}{|lr|}
\hline Campo de Atuação & Respostas \\
\hline Organização e administração de laboratórios de informática. & $12(100 \%)$ \\
Capacitação de professores e comunidade escolar, segundo critérios da escola para & $12(100 \%)$ \\
trabalhar com informática educativa. & $10(86,3 \%)$ \\
Elaboração e participação em projetos na área de Ensino a Distância (EAD). & $8(66,7 \%)$ \\
Pesquisa em tecnologia na área da Informática. & $8(66,7 \%)$ \\
Criação, utilização e avaliação de software educacional. & $8(66,7 \%)$ \\
Desenvolvimento de materiais instrucionais através do emprego da informática. & $8(66,7 \%)$ \\
Assessoria às instituições educativas que constroem propostas pedagógicas. & $8(66,7 \%)$ \\
\hline
\end{tabular}

Além disso, foi perguntado se os participantes da pesquisa conseguiram alguma colocação profissional após o término do curso. Apenas $50 \%$ conseguiram, atuando como tutores presenciais do próprio curso, operador de AVA, técnico de Tecnologia da 
VII Congresso Brasileiro de Informática na Educação (CBIE 2018)

Anais dos Workshops do VII Congresso Brasileiro de Informática na Educação (WCBIE 2018)

Informação (TI), professor de Informática básica e professor do LEI. Para esse grupo foram realizados os seguintes dois questionamentos.

O primeiro foi acerca das habilidades e competências desenvolvidas durante o curso que foram utilizadas na sua atuação profissional. A Figura 1 apresenta o resultado desse questionamento, indicando que a maioria concorda que as competências "analisar e escolher softwares educativos para a melhoria do processo de ensino e aprendizagem" e "ampla formação teórica tecnológica em Computação" foram as mais utilizadas na atuação profissional deles.

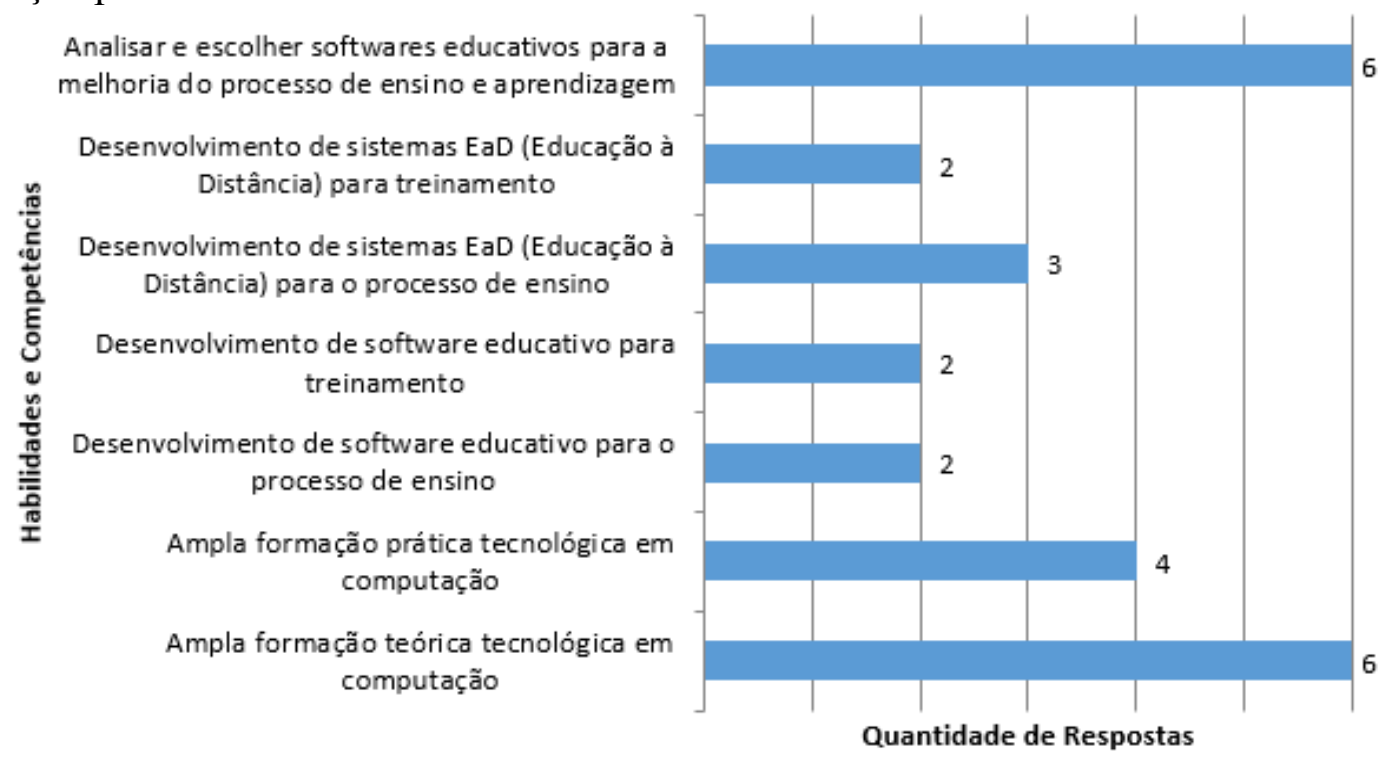

Figura 1. Habilidades e competências utilizadas durante a atuação profissional

O segundo questionamento foi sobre o campo de atuação que o emprego se enquadrava. A Figura 2 apresenta o resultado dessa análise, na qual todos que responderam a esta pergunta citaram a organização e administração do LEI como campo de atuação profissional pelo qual o curso the habilitou. Por outro lado, os campos de criação, utilização e avaliação de software educacional, bem como elaboração e participação em projetos na área de ensino a distância (EaD), seguido por assessoria as instituições educativas que constroem propostas pedagógicas foram as menos citadas por parte dos entrevistados. Vale ressaltar que cada campo de atuação sugerido pelo PPC foi ocupado por, pelo menos, um licenciado.

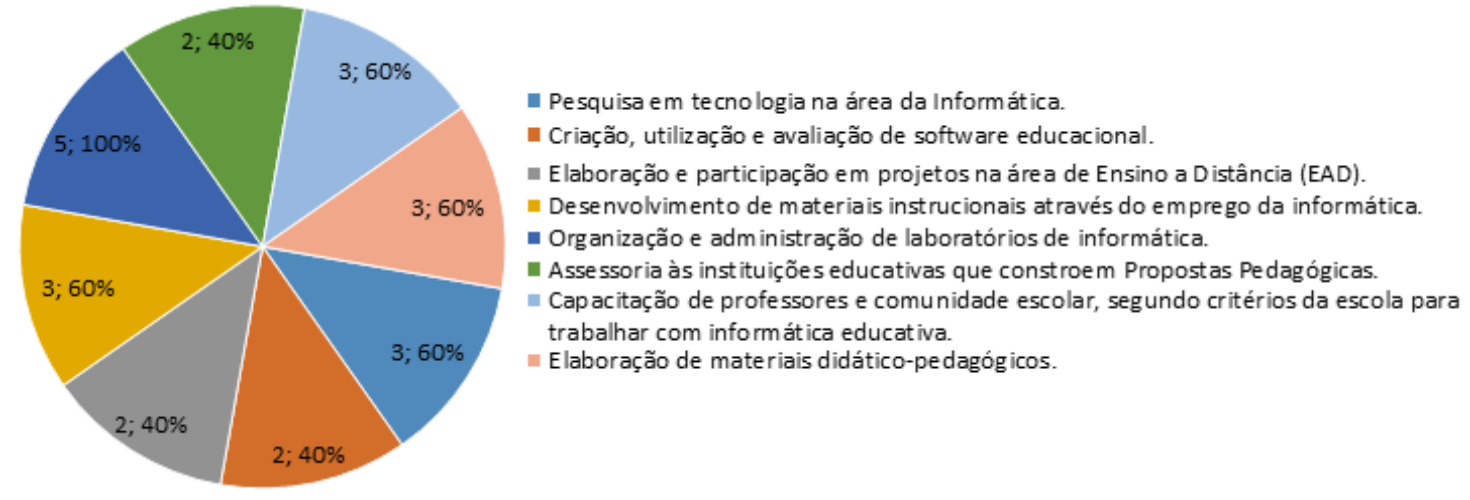

Figura 2. Campos da atuação profissional 
VII Congresso Brasileiro de Informática na Educação (CBIE 2018)

Anais dos Workshops do VII Congresso Brasileiro de Informática na Educação (WCBIE 2018)

Finalmente, foi questionado a todos os participantes quais eram os campos eles poderiam atuar com o que foi aprendido por eles no curso de licenciatura da Computação. As respostas a essa questão foram sintetizadas na Tabela 3. Essa tabela foi dividida em duas partes: uma com as respostas relacionadas à atuação na área técnica e outra ao campo educacional, tendo em vista que a licenciatura em Computação tem como norte as duas áreas de atividades, como é exemplificado por [Sampaio 2014], "além do exercício profissional de magistério em Computação no ensino básico, e da capacitação na elaboração e aplicação de projetos de Informática educativa, o egresso terá ampla formação tecnológica em Computação, conceitual e prática, habilitando-o ao desenvolvimento e implementação de produtos e soluções de Informática voltada ao ensino e treinamento, desde software educativo até sistemas de educação a distância".

Assim é notório que a atuação docente no LEI seria o campo de atuação mais lembrado pelos participantes da pesquisa. Entretanto, esse campo já é previsto no PPC. Além disso, a área de desenvolvimento de software foi listada como um possível campo, porém "necessitaria de um treinamento mais específico e com mais tempo de estudo e prática" (Formado 10).

Tabela 3. Síntese de respostas em relação aos possíveis campos de atuação

\begin{tabular}{|c|c|}
\hline $\begin{array}{l}\text { Outro campo de atuação na area tecnica } \\
\text { (justificativas) }\end{array}$ & $\begin{array}{c}\text { Outro campo de atuação na area educacional } \\
\text { (justificativas) }\end{array}$ \\
\hline $\begin{array}{l}\text { "Os campos são vastos, nos falta oportunidades para exercermos a } \\
\text { nossa profissão, pois, ouvimos muito sobre a importância das } \\
\text { tecnologias na educação, porém, os profissionais formados na } \\
\text { área não são aproveitados". } \\
\text { "Na área da computação, o campo é amplo e muito flexivel, } \\
\text { possibilitando assim o licenciado em Computação exercer sua } \\
\text { função tanto no âmbito educacional como empresarial". } \\
\text { "No campo da tecnologia como na criação de software, por } \\
\text { exemplo. Porém, necessitaria de um treinamento mais específico e } \\
\text { com mais tempo de estudo e prática". } \\
\text { "todos os campos que envolvam tecnologia". }\end{array}$ & $\begin{array}{l}\text { "Professor do ensino básico e superior". } \\
\text { "Nos permite atuar em atividades que necessitem de } \\
\text { conhecimentos científicos em informática/computação". } \\
\text { "Escolas e faculdade". } \\
\text { "Sala de aula, laboratório de informática". } \\
\text { "Segurança para promover o ensino aprendizagem } \\
\text { utilizando as TICs". } \\
\text { "Para mim, só na área docente". } \\
\text { "Laboratório". }\end{array}$ \\
\hline
\end{tabular}

\section{Considerações Finais}

O presente artigo teve como objetivo desvelar a área de atuação dos alunos egressos do curso de Licenciatura em Computação ofertado pela Universidade Estadual do Ceará (UECE) no polo de apoio presencial situado em Mauriti/CE. Para tanto, foi realizada uma pesquisa descritiva utilizando questionário como instrumento de coleta de dados. Os sujeitos de pesquisa foram os egressos dos referidos curso e polo de apoio presencial.

Assim, ao cumprir com o objetivo da pesquisa, foi identificado que os campos possíveis de atuação eram (i) pesquisa em tecnologia na área da Informática, (ii) criação, utilização e avaliação de software educacional, (iii) elaboração e participação em projetos na área de Ensino a Distância (EAD), (iv) desenvolvimento de materiais instrucionais através do emprego da Informática, (v) organização e administração de laboratórios de Informática, (vi) assessoria às instituições educativas que constroem Propostas Pedagógicas, (vii) capacitação de professores e comunidade escolar, segundo critérios da escola para trabalhar com Informática educativa, e (viii) elaboração de materiais didático-pedagógicos. 
VII Congresso Brasileiro de Informática na Educação (CBIE 2018)

Anais dos Workshops do VII Congresso Brasileiro de Informática na Educação (WCBIE 2018)

Além disso, foi verificado que todos os possíveis campos de atuação foram ocupados por, pelo menos, um licenciado (Veja a Figura 2). Portanto, o PPC do referido curso retrata os campos reais de atual dos seus egressos. Vale ressaltar que, os licenciados indicaram que o principal campo de atuação seria atuar como docente no LEI e que a área de desenvolvimento de software seria um campo desejável.

Como trabalhos futuros, sugere-se a complementação dessa pesquisa por meio da inclusão de outros polos que oferecem o curso de Licenciatura em Computação da UECE. Portanto, seria possível ter uma visão mais abrangente dos egressos do referido curso. Além disso, a metodologia desse estudo por ser reutilizada para analisar outros cursos.

\section{Agradecimentos}

Os autores agradecem ao polo de apoio presencial de Mauriti/CE por disponibilizar os contatos dos egressos do curso e aos participantes da pesquisa por responder voluntariamente ao questionário proposto.

\section{Referências}

Araújo, D. F. (2010) "O Curso de Licenciatura em Computação do Campus VII da UEPB sob a Visão dos Discentes". Trabalho de Conclusão de Curso (Graduação em Computação) - Universidade Estadual da Paraíba, Patos.

Joye, C. R. (2014) Metodologia Científica. Fortaleza: SETEC/IFCE, 2014.

Luciano, A. P. C. e Santos, A. A. (2013) "Caminhos do Licenciado em Computação no Brasil: Estudo de Mercado a partir de uma Pesquisa com Egressos”, In: Simpósio Brasileiro de Informática na Educação, Campina Grande. Anais do II Simpósio Brasileiro de Informática na Educação.

Paiva, F. (2017) "A Formação, o Trabalho e a Identidade Profissional do Professor de Computação: Um Mapeamento sobre a Licenciatura em Computação”, In: Congresso Brasileiro de Informática na Educação, 2017, Salvador. Anais dos Workshops do VI Congresso Brasileiro de Informática na Educação.

Públio Junior, C. (2018) "Formação Docente Frente as Novas Tecnologias: Desafios e Possibilidades", In: Intermeio: Revista do Programa de Pós-Graduação em Educação, Campo Grande, MS, v. 47, n. 24, p.189-210.

Rapkiewicz, C. E.; Xexéo, J. A. M.; Freitas, M. F.; Souza, I. F.; Delgado, C. A. D.M. e Campos, M. F. (2004) "O Campo de Atuação para Licenciandos em Computação: Um Estudo de Caso no Norte Fluminense", In: Congresso da Sociedade Brasileira de Computação, Rio de Janeiro. Anais do XXIV Congresso da Sociedade Brasileira de Computação.

Sampaio, J. J. C. (2014) Projeto Político Pedagógico Licenciatura em Computação a Distância. Disponível em: http://www.uece.br/computacaoead/index.php/downloads/ doc_download/2052-pcccomputacao. Acessado em 15 jul. 2018.

Santos, W. O.; Silva, C. C. V. e Hinterholz, L. T. (2017) "Licenciatura em Computação: Desafios e Oportunidades na Perspectiva do Estudante", In: Congresso Brasileiro de Informática na Educação, Recife. Anais do VI Congresso Brasileiro de Informática na Educação. Recife: Sociedade Brasileira de Computação. 